Bolm. Zool., Univ. S. Paulo

$9: 145-157,1985$

\title{
ALGUNS OLIGOCHAETA DO NORTE E NOROESTE DO BRASIL
}

GILBERTO RIGHI

Departamento de Zoologia, Instituto de Biociências, Universidade de São Paulo.

RAFAEL A. T GUERRA

Departamento de Ciéncias da $\mathrm{Na}-$ tureza, Universidade Federal do Acre. (recebido em 11.X.1984)

RESUMO - São estudadas 16 espécies de Oligochaeta do norte e noroeste do Brasil. A Ocnerodrilidae, Eukerria emete, sp. n. e a Glossoscolecidae, Chibui bari, gen. n., sp.n. săo descritas. São apresentadas novas observações sobre Martio drilus matapi. Novas ocorréncias são indicadas para as Ocnerodrilidae: Gordiodrilus habessinus, Eukerria eiseniana, $E$. urna, Nematogenia Zacuum; Octochaetidae: Dichogaster bolaui, D. gracilis, D. modiglianii, D. saliens; Glossoscolecidae: Martiodrilus matapi, Rhinodrilus curiosus, Pontoscolex (P.) corethrurus, Goiascolex pepus, Diaguita vivianeae e Glos8o drilus tocantinensis pola.

ABSTRACT - From north and northwest of Brazil, 16 species of Oligochaeta are studyed. The Ocnerodrilidae, Eukerria emete, sp. n. and the Glossoscolecidae, Chibui bari, gen. n., sp. $\mathrm{n}$. are described. New data are given on Martiodrilus matapi. New occurrences are indicated to Ocnerodrilidae: Gordiodri Zus habessinus, Eukerria eiseniana, E. urna, Nematogenia Lacuum; Octochaetidae: Dichogaster bolaui, D. gracilis, D. modiglianii, D. saliens; Glossoscolecidae: Martiodrilus mata pi, Rhinodrilus curiosus, Pontoscolex (P.) corethrurus, Goias colex pepus, Diaguita vivianeae and Glossodrilus tocantinensis pola.

Nesta publicação estão reunidos animais coletados por G. Righi nos Estados de Mato Grosso e Rondōnia em 02/1984 e no Território de Roraima em 12/1979, bem como animais obti dos por R. A. T Guerra no Estado do Acre em 10 - 12/1983.As coletas em Mato Grosso e Rondónia foram subvencionadas pelo Conselho Nacional do Desenvolvimento Científico e Tecnológico - Polo Noroeste (Righi, 1983; 1984) e em Roraima pela Secretaria Especial do Meio Ambiente, Ministério do Interior (Righi, 1982a; b) a quem agradecemos. 
Os estudos foram feitos em animais fixados em formalina 108, dissecados e em cortes histológicos, $10 \mu \mathrm{m}$, corados pelo método tríplice de Mallory (Pantin, 1964) 0 material está depositado no Departamento de Zoológia, Universidade de São Paulo.

\section{Lista das localidades de coleta}

Mato Grosso:

A - Pontes e Lacerda $\left(15^{\circ} 12^{\prime} S\right.$ - $\left.59^{\circ} 20^{\prime} W\right)$, pomar próximo do Rio Guaporé.

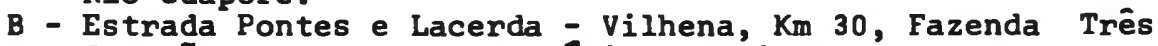
Coraçōes, solo arenoso próximo do Rio Branco.

C - Estrada Pontes e Lacerda - Vilhena, Km 45, Fazenda Três Irmãos, solo argilo-arenoso com capim colonião (Panicum maximum), próximo de represa.

D - Estrada Pontes_e Lacerda - Vilhena, $\mathrm{Km}$ 60, Fazenda Sapé, solo arenoso, úmido, com Gramineae, próximo de córrego.

E - Estrada Pontes e Lacerda - Vilhena, Km 60, Fazenda Sapé, solo argilo-arenoso, rico em húmus, com capim coloniảo (Panicum maximum).

F - Estrada Pontes e Lacerda - Vilhena, Km 88, Fazenda Cerejeiras, solo argilo-arenoso, próximo do Rio Seixas.

G - Estrada Pontes e Lacerda - Vilhena, Km 123, Fazenda Pa raíso, região alagada.

H - Estrada Pontes e Lacerda - Vilhena, Km 180, Fazenda Guaporé, solo argilo-arenoso, rico em hưmus, próximo de cor rego.

I - Nova Alvorada $\left(13^{\circ} 42\right.$ 's - 59 $\left.53^{\circ} \mathrm{W}\right)$, solo argilo-arenoso, rico em húmus, transição mata - plantaçāo de café.

$J$ - Estrada Pontes e Lacerda - Vilhena, Km 250, Barracāo Que i mado, solo arenoso, preto, na margem do Rio Mutum.

Rondônia:

K - Vilhena $\left(12^{\circ} 45^{\prime} \mathrm{S}-60^{\circ} 09^{\prime} \mathrm{W}\right)$, arredores da cidade, solo arenoso com Gramineae.

Acre: Rio Branco $\left(9^{\circ} 58^{\prime} \mathrm{S}-67^{\circ} 48^{\prime} \mathrm{W}\right)$ :

L - Pomar com buritis (Mauricia flexuosa) e mangueiras (Mangifera indical, solo areno-argiloso, úmido.

M - Campo com Gramineae e árvores queimadas, solo arenoso, 뜨 mido.

N - Campus da Universidade Federal do Acre, solo argiloso, pouco úmido, de capoeira.

o - Buritizal da Corrente, solo areno-argiloso, encharcado, com matéria orgânica em decomposição.

P - Chácara do Ipé, solo preto com Gramineae.

Roraima:

Q - Ilha de Maraça $\left(3^{\circ} 20^{\prime} \mathrm{N}-61^{\circ} 40^{\prime} \mathrm{W}_{3}\right.$ ilha do Rio Uraricoe ra), solo próximo do Canal Maracả.

R - Ilha de Maracă, solo na margem de igarapé.

$S$ - Ilha de Maracá, solo arenoso com matéria orgânica em decomposição, fundo de lagoa seca. 
T - Estrada Boa Vista - Bonfim, Km 100, Fazenda Santana, solo da margem de igarapé.

$U$ - Bonfim ( $\left.30_{15}^{\prime} \mathrm{N}-59^{\circ} 52^{\prime} \mathrm{W}\right)$, solo arenoso da margem do Rio Itacotu.

\section{Ocnerodrilidae \\ Gordiodrilus habessinus Michaelsen, 1913}

Gordiodrilus habessinus Michaelsen, 1913: 5, fig. 2, est.II, figs. 30-31; Righi, 1980, figs. 30-31; 1984 .

Material - Localidade B, 2 clitelados (ZU-763) Localidade I, I clitelado e I jovem (ZU-768). Localidade K, II clitelados e 4 jovens ( $Z U-769$ )

\section{Eukerria eiseniana (Rosa, 1895)}

Kerria eiseniana Rosa, 1895: 2.

Eukerria eiseniana; Righi, 1980 ; 1984.

Material - Localidade B, 2 clitelados e 1 maduro aclitelado (ZU-762). Localidade C, 1 clitelado (ZU-774). Localidade S, 25 clitelados, 17 maduros aclitelados e 5 jovens ( $Z U-786$ ). Lo calidade T, 8 clitelados ( $\mathrm{ZU}-787$ )

\section{Eukerria urna Righi, 1968}

Eukerria urna Righi, 1968: 183, figs. 6-8; 1971: 3 .

Material - Localidade U, 1 clitelado (ZU-789)

\section{Eukerria emete, sp. n \\ (Figs. 1-5)}

Material - Localidade D, 2 clitelados, 3 maduros aclitelados e 1 jovem (ZU-764). Localidade F, I clitelado (ZU-765) Loca lidade G, 21 clitelados (ZU-766) Localidade I, 3 clitelados, 5 maduros aclitelados e 15 jovens ( $\mathrm{ZU}-767$ ).

Descrição - Comprimento 52 - $58 \mathrm{~mm}$. Diâmetro na regiāo média 1,1 - 1,2 mm. Nümero de segmentos 133 - 146. Pigmento falta. Prostômio epilobo $1 / 3$ com língua aberta ou fechada. Cerdas dispostas em 8 séries longitudinais regulares a partir de II. As cerdas são sigmóides, de ponta simples, superfície li sa e nódulo no início do $1 / 3$ distal. Na região média do corpo (segmentos XXX - XL), $a a: a b: b c: c d: d d=4,3: 1,0$ $: 4,8: 5,0: 14,2$. Faltam as cerdas $b$ em XVII - XIX. Nefridioporos irreconhecíveis. Poros dorsais faltam.

Clitelo em $1 / 2$ XIII - XIX $(=61 / 2)$, em forma de anel 
pouco espesso ventralmente ou em forma de sela com limite in ferior na linha $a$; sulcos intersegmentares irreconhecíveis na regiāo clitelar. Poros prostáticos diminutos situam-se na linha $b$ de XVII - XIX, no ápice de papilas de base circular a ovóide, restritas aos proprios segmentos (Figs. 1 - 2) As papilas de cada lado são unidas entre si por um par de tra ves pouco mais baixas do que as papilas e alinhadas com $a b$. Em alguns animais as traves são percorridas por uma faixa es cura, mediana e longitudinal, sulcos seminais aprofundados faltam. 0 par de poros masculinos situam-se em XVIII, na linha média das traves, lateralmente às cerdas $a$. De 27 ani mais maduros observados, 13 apresentam 2 pares de papilas pu bertais arredondadas, pouco salientes e pouco mais escuras do que o epitélio circunjacente, situadas em 16/17 e 19/20, na linha das papilas prostäticas; faltam as papilas de $16 / 17$ em 5 animais e faltam os 2 pares de papilas em 9 animais. Pa pilas semelhantes ocorrem em linha com as cerdas $b$ na metade anterior de IX em 1 animal e de IX e X em outro. 0 par de po ros femininos situa-se na regiäo anterior de XIV, na linha $b$. Dois pares de poros de espermatecas situam-se em série com as cerdas $b$, em $7 / 8$ e $8 / 9$, no interior de reentrâncias fusiformes, ora mais ora menos demarcadas.

Os septos $5 / 6$ - $8 / 9$ säo bastante espessos e musculo sos, de $9 / 10$ - $11 / 12$ tornam-se sucessivamente mais delgados, de $11 / 12$ para trâs são frâgeis. Glândulas septais chegam atè VIII. Em VII encontra-se uma moela musculosa, com forma de tronço de cone e de diâmetro cerca de 2 vezes maior do que - esôfago adjacente. Um par de glândulas calcíferas ocupa ventralmente toda a extensão de IX, onde se abre na região látero-ventral e posterior do esôfago através de um par de dutos curtos e dobrados em cotovelo. A estrutura das glândulas é mais ou menos maciça (Fig. 5), compõe-se de um sistema de espaços sanglíneos longitudinais interligados, predominan do as ligações radiais e entremeados por delgados canalícu los glandulares que se abrem em 2 canais principais ciliados. Os 2 canais principais percorrem todo o corpo glandular, fun dindo-se entre si na região do duto, que apresenta lume úni= co. A transição esôfago-intestino situa-se em $11 / 120$ intes tino é dilatado em XII - XIII, delgado em XIV - XIX e de diâa metro pouco maior e regular para trás. Tiflosole e cecos intestinais faltam. Em X e XI encontram-se 2 pares de volumo sas alças sanglíneas comissurais. Em cada segmento, a partir de $x$, hà um par de holonefridios avesiculados. Um par de tes ticulos e de funis seminais prateados situa-se em $X_{2}$ cuja că vidade estâ cheia de espermatozóides em diferenciaçăo. Vesículas seminais pares, de superfície lobulada, situam-se em $X$ e XI. As do segundo par são mais desenvolvidas, circundando - esôfago dorsal e lateralmente. Dois pares de próstatas prendem-se em XVII e XIX. Em cada próstata o duto é delgado, sem dilatação ectal e de comprimento equivalente a 1/2 seg mento. A parte glandular é cerca de 2 vezes mais larga e estende-se ventralmente ao intestino por 2 - 3 segmentos. Os dutos seminais são retos e superficiais na parede do corpo a tê $1 / 2$ XVIII, quando penetram na musculatura parietal. U⿳亠丷⿵冂丶 par de ovários em forma de espátula longa e estreita e um 
par de funis femininos encontram-se em XIII. Dois pares de espermatecas elevam-se dos lados do esôfago em VIII e IX. Em cada espermateca (Figs. 3 - 4) a ampola é saquiforme e dobra -se sobre si mesma no terço ectal, seu epitélio é glandular. Uma constrição nítida separa a ampola do duto. 0 duto dobrase sobre si mesmo 1 - 2 vezes, dependendo do seu comprimen to, que pode ser equivalente ou maior do que o da ampola. Es permatozoides podem estar armazenados em toda a espermateca (Fig. 5) ou apenas na metade ectal do duto.

Consideraçōes - 0 campo genital masculino de Eukerria emete assemelha-se ao de $E$. stagnalis pela presença de 1 par de pa pilas pubertais anterior as papilas prostáticas de XVII e ou tro posterior às de XIX. Contudo, as 2 espécies distinguem se pela moela, glāndulas calcíferas e próstatas. Comparando com as espécies de Eukerria que apresentam glândulas calcífe ras gordiodrilóides e poros das espermatecas na linha das cerdas ventrais, $E$. emete distingue-se pelos caracteres se guintes:

E. papilizfera (Rosa, 1895) - Estrutura das glândulas calciferas desconhecida. Papilas pubertais ímpares, media nas e ventrais em XIV - XVI. Prốstatas associadas cóm câma ras copulatórias.

E. peguana Gates, 1942 - Papilas pubertais em XX e/ou XXI, ou faltam. Espermatecas diminutas. Uma invaginação ventral, transversal em XVII e XIX contem o que devem ser peque nas papilas prostäticas.

E. santafesina Ljungstrom, 1972 - Sulcos seminais convexos lateralmente. Papilas pubertais transportam as cerdas $a b$ de XVIII. Uma invaginação ventral, transversal em XVII e $X I X$ contem os poros prostaticos.

O nome da nova espécie é pal
Pacaá-Nova e significa "minhoca"

\section{Nematogenia Zacuum (Beddard, 1893)}

Pygmaeodrilus Zacuum Beddard, 1893: 259, est. 26, figs. 13 16 .

Nematogenia Zacuum; Righi, 1984.

Material - Localidade A, 1 maduro aclitelado (ZU-770) Localidade $\mathrm{D}$, 15 clitelados, 94 maduros aclitelados $e 11$ jovens (ZU-760) Localidade G, 1 clitelado, 15 maduros aclitelados e 3 jovens ( $Z U-761)$

Octochaetidae

Dichogaster bolaui (Michaelsen, 1891)

Benhamia bolavi Michaelsen, 1891: 307, figs. 1-2. Dichogaster bolaui; Righi et all. 1978: 38; 1983, figs. 3 $4 ; 1984$. 
Maíerial - Localidade D, 1 clitelado, 1 maduro aclitelado e 1 jovem ( $\mathrm{ZU}-778$ ). Localidade G, 1 clitelado (ZU-780). Locali dade L, 2 clitelados (ZU-796). Localidade M, 3 clitelados(ZU -806). Localidade $Q, I$ clitelado ( $\mathrm{ZU}-783$ ). Localidade $R, I$ clitelado (ZU-785). Localidade $U, 4$ clitelados $e 1$ maduro aclitelado (ZU-788).

\section{Dichogaster gracilis (Michaelsen, 1892)}

Benhamia gracilis Michaelsen, 1892: 258, figs. Cl-2. Dichogaster gracilis; Righi, 1984, figs. 1-7.

Material - Localidade D, 2 clitelados (ZU-779) Localidade $\mathrm{K}, \mathrm{I}$ maduro aclitelado $\mathrm{e} 3$ jovens ( $\mathrm{ZU}-777$ )

\section{Dichogaster modiglianii (Rosa, 1896)}

Benhamia modiglianii Rosa, 1896: 510, est. 1, figs. la-b. Dichogaster modiglianii; Righi et all. 1978: 38; Righi,1980; 1984 .

Material - Localidade B, I clitelado (ZU-772) Localidade C, 10 clitelados, 2 maduros aclitelados e 3 jovens (ZU-771). Lo calidade $Q, 8$ clitelados ( $\mathrm{ZU}-782$ )

\section{Dichogaster saliens (Beddard, 1892)}

Microdrilus saliens Beddard, 1892: 683, est. 46, figs. 8,13. Dichogaster saliens; Righi et all. 1978: 39; Righi, 1980; $1983 ; 1984$.

Material - Localidade L, 1 clitelado (ZU-801).

\section{Glossoscolecidae}

$$
\text { Martiodrilus matapi (Righi, 1969) }
$$

Thamnodrilus matapi Righi, 1969: 42, figs. 1 - 4. Material - Localidade 0, 2 clitelados e 1 jovem (ZU-804).

Consideraçōes - A espécie era conhecida apenas pela descri ção original de animais do Amapá. À descrição original acres cento: um par de cecos pequenos e arredondados partem de cada lado da linha média ventral do intestino em XXVII. 0 ti flosole dorsal tem a forma de uma lámina dobrada em $\mathrm{S}$ e tão alta quanto o diâmetro intestinal.

Os animais do Acre diferem dos do Amapā por um espes samento glandular ventral em XV, que contem as cerdas ven trais, também transformadas em cerdas genitais. 
Rhinodrilus curiosus Righi et all. 1976

Rhinodrilus curiosus Righi et all. 1976: 356, figs. 38 - 42.

Material - Localidade N, 6 clitelados, 10 maduros aclitela dos e 14 jovens ( $\mathrm{ZU}-798$ ) Localidade $\mathrm{P}, 9$ clitelados, 3 madu ros aclitelados, 2 jovens e 1 casulo ( $Z U-793$ )

\section{Pontoscolex (P.) corethrurus (MUller, 1857)}

Lumbricus corethrurus Muller, 1857: 113.

Pontoscolex (P.) corethrurus; Righi, 1982b.

Material - Localidade A, 17 clitelados, 45 maduros aclitelados e 30 jovens ( $Z U-757)$. Localidade $B, 3$ clitelados, 3 madu ros aclitelados e 1 jovem (ZU-758). Localidade $C$, I clitela= do e 1 maduro aclitelado ( $\mathrm{ZU}-773$ ) Localidade $\mathrm{D}, 12$ clitelados, 8 maduros aclitelados e 14 jovens ( $\mathrm{ZU}-759$ ) Localidade $G, 4$ clitelados e 8 jovens (ZU-750). Localidade $\mathrm{H}, 53$ clitelados, 7 maduros aclitelados e 20 jovens ( $\mathrm{Zu}-752 \mathrm{~A}-\mathrm{B})$ Locali dade I, 8 clitelados, 11 maduros aclitelados e 25 jovens ( $Z \bar{U}$ -751). Localidade $\mathrm{J}, 7$ clitelados, 1 maduro aclitelado e 3 jovens (ZU-754). Localidade $K, 10$ clitelados, 5 maduros acli telados e 19 jovens $(\mathrm{ZU}-753)$. Localidade $\mathrm{L}, 45$ clitelados $\bar{e}$ 21 maduros aclitelados (ZU-795, 800). Localidade $\mathrm{M}, 3$ clitelados, 1 maduro aclitelado e 3 jovens (ZU-805). Localidade 0 , 49 clitelados, 6 maduros aclitelados e 12 jovens ( $\mathrm{ZU}-803$ ) Localidade $\mathrm{P}, 2$ clitelados (ZU-794)

\section{Goiascolex pepus Righi, 1972}

Goiascolex pepus Righi, 1972: 153, figs. 4- 6; 1984.

Material - Localidade D, 17 clitelados, 6 maduros aclitela dos e 7 jovens (ZU-756A-B). Localidade F, 3 clitelados e 2 maduros aclitelados ( $\mathrm{ZU}-757$ ) Localidade $\mathrm{H}, 21$ clitelados, 9 maduros aclitelados e 30 jovens (ZU-759A-B). Localidade $I, 4$ clitelados, 9 maduros aclitelados e 4 jovens ( $Z U-758 \mathrm{~A}-\mathrm{B})$.

$$
\text { Chibui, gen. n. }
$$

Diagnose - Cerdas, 8 por segmento, dispostas em sëries longi tudinais regulares. Poros maculinos, 1 par, intraclitelares. Moela em VI. Trés pares de glândulas calcíferas pedunculadas e de estrutura tubular dicotômica (paniculada) em VII - IX Vasos supra- e subesofágicos e subneural presentes. Coraçōes laterais em VII - IX e coraçōes intestinais em X - XI. Holonefridial. Proândrico e metagínico. Vesículas seminais cur tas. Um par de câmaras copulatórias. Espermatecas presentes, pretesticulares.

Tipo do gènero - Chibui bari, sp. n. 
Consideraçōes - Rhinodrilus, Pontoscolex, Opisthodrilus, Goiascolex e Chibui formam um grupo de Glossoscolecidae ca racterizado por apresentar 3 pares de glândulas calcíferas em VII - IX. Chibui distingue-se por ser proândrico e apre sentar um par de câmaras copulatoorias. Os demais géneros são holāndricos (Rhinodrilus, Goiascolex) ou metândricos (Pontos colex, Opisthodrilus) e os dutos masculinos abrem direto na superfície, sem câmaras copulatórias, exceto Goiascolex com câmara copulatōria ímpar.

o nome Chibui e usado pelos indígenas da Amazônia para designar minhoca grande, minhocuçu.

\section{Chibui bari, sp. n. \\ (Figs. 6-10)}

Material - Localidade L, 1 clitelado fragmentado e 1 jovem (ZU-799). Localidade $N$, 1 maduro aclitelado e 2 jovens ( $U$ U 797). Localidade $P, 4$ clitelados ( 3 fragmentados), 2 jovens e 7 casulos ( $\mathrm{ZU}-792$ )

Descrição - Comprimento do clitelado inteiro $265 \mathrm{~mm}$. Diâme tro na região média 9 - $10 \mathrm{~mm}$. Número de segmentos 205 . Cor no dorso cinza escura semelhante à do no 643 de Séguy(1936), ventre esbranquiçado; o limite entre as cores é brusco na lí nha dos nefridióporos. Uma linha de pontos esbranquiçados percorre dorsalmente o equador de cada segmento. Clitelo de cor marrom avermelhada como a do n! 118. Prostómio tentacu lirforme, invaginado com os segmentos I - II que são rudimen tares. Segmentos III com numerosos sulcos longitudinais. Cer das dispostas em 4 pares de séries longitudinais regulares, as ventrais iniciam-se em VI - VII e as laterais apos o clitelo. Em VII e IX, podendo ocorrer também em VIII ou $X$, as cerdas $a$ estão deslocadas medial e posteriormente e as cerdas $b$ para a linha dos poros das espermatecas. Na região média do corpo, segmentos XL - L, as relações entre as cerdas são $a a: a b: b c: c d: d d=8,5: 1,0: 11,3: 0,5: 29,8$ As cerdas comuns são sigmóides, alongadas, com nódulo ligeiramente distal e $01 / 5$ apical apresenta 4 séries alternas de escavações semilunares, largas e abertas para o ápice; con tam-se 4 escavações em cada série. 0 comprimento das cerdas na região média varia de $616-728 \mu \mathrm{m}$, sendo as ventrais mai ores. As cerdas ventrais de XVI, XVII - XXIII transformam-se em genitais. Elas são retas, com ligeira curvatura proximal e o comprimento varia de 1,35 - 1,79 $\mathrm{mm}_{3}$ em média $1,61 \mathrm{~mm} e$ - diâmetro proximal de 47 - $58 \mu \mathrm{m}$, em mêdia $53 \mu \mathrm{m}$. Seus $2 / 5$ apicais são ornamentados por 4 séries alternas de escavações semilunares, há 9 - 13 escavaçōes por sêrie, em geral 12 .

0 clitelo ocupa os segmentos XVI, 1/2 XVI, XVII - XXV $(=9-10)$ Tem forma de sela, bastante túrgido, com sulcos intersegmentares nítidos e o limite inferior pouco lateral a linha de cerdas $b$ (Fig. 6) A face ventral de XIX - XXIII é pregueada longitudinalmente. A face ventral de XXI é aprofun dada como un quadrilátero em $a a$, e mais aprofundada lateralmente, onde forma um par de amplas câmaras copulatörias, cu- 
ja abertura é formada pela aposição das margens de XX e XXI (Figs. 6, 10), Âreas circulares diferenciadas envolvem as cerdas $a$ e $b$ de VII - X e de XV, XVI - XXIII, correspondendo a grupos de células glandulares intraparietais que envolvem as cerdas ( $\mathrm{Fig}, 10$ ).

Os septos anteriores são cônicos e interpenetrados, os $6 / 7$ - 8/9 săo espessos e musculosos, os seguintes afilam gra dualmente até $15 / 16$ Os septos seguintes sâo delgados, exceto os 19/20 - 22/23, que são especialmente musculosos na região das câmaras copulatórias (Fig. 10). Cada septo anterior prende-se ventralmente na altura do intersegmento correspondente e dorsalmente na metade do segmento seguinte. 0 esofago anterior é largo e longo, dobrado em $S$ e cheio de terra. Segue-se uma moela globóide, muito musculosa, em VI. Três pa res de glândulas calcíferas abrem-se dorsalmente no esôfagō posterior em VII - IX. Cada glândula (Fig. 7) é formada por um duto pequeno e por um corpo ovóide, achatado lateralmente e de estrutura tubular dicotomica (paniculada) 0 intestino inicia-se en XV e alarga-se após o clitelo. Cecos intesti nais faltam. 0 tiflosole dorsal inicia-se em XXVI e tem a forma de uma lâmina dobrada em $S$, tão alta quanto o diâmetro intestinal. Dois pares de coraçöes intestinais volumosos situam-se em $X$ e XI e 3 pares de delgados corações laterais em VII - IX. Vaso subneural presente. Em cada segmento há um par de holonefrídios com nefridióporos nos intersegmentos ou imediatamente atrás, na linha $c$ ou $c d$. Os nefrídios de VI e anteriores enovelam-se de cada lado do esôfago.

Um par de testículos e de largos e pregueados funis se minais situam-se em $X$, no interior de um saco testicular volumoso que envolve o esôfago como um anel largo. Um par de vesículas seminais volumosas situa-se em XI. O canal deferen te de cada lado corre para trás, fazendo pequenas ondula = çōes, aderido a uma faixa muscular oblíqua no interior da ca vidade do corpo, pouco lateral e superiormente à cadeia nervosa, até a parede ventral de XVII, onde se origina a faixa muscular. 0 canal deferente dirige-se então para o lado e a seguir para trás, na parte mais interna da musculatura parie tal, atê à câmara copulatória correspondente, onde se abre Cada câmara copulatória ocupa quase todo o espaço lateral dos segmentos XX - XXII (Fig. I0), apõe-se à parede dorsal de XX e XXII, deixando pequeno espaço triangular dorsal em XXI. Um par de ovários situa-se em XIII, aderido à face ante rior de 13/14, dos lados do vaso ventral. Cada ovário é flabelar, ondulado, com ovos dispostos mais ou menos em séries; a maturação dos ovos parece ser sincrônica, distinguindo-se 3 faixas da base para o ápice. Lateralmente a cada ovário si tua-se un funil feminino discóide. Dois pares de espermate cas situam-se em VIII e IX e abrem-se em $7 / 8$ e $8 / 9$, no terço ventral de $b c$, junto de uma área pregueada, posterior em VII e VIII. As espermatecas são saquiformes e as do segundo par são quase 2 vezes maiores. A distinção entre duto $e$ ampola (Fig. 8) só è possível em cortes devido à espessura de sua parede. Em cada espermateca o duto está quase todo mergulhado na musculatura parietal, seu comprimento equivale a metade do comprimento da ampola e tem numerosas camaras seminais 
irregulares e cheias de espermatozóides, no interior da pare de. A ampola só contem uma massa albuminóide.

Casulos - Os casulos observados contêm 0 - 2 embriōes bem di ferenciados. Um casulo pronto para eclodir contem só 1 em brião. Não hả diferenças marcantes quanto à forma, tamanho e cor entre os casulos embrionados e não embrionados. Eles têm a forma de um cilindro curto e largo, com extremidades arredondadas (Fig. 9) e cor amarela clara como a do ne 228 de Sé guy (1936). Os polos são marcados por um anel marrom escuró como o no 112, envolvendo pequena área clara. 0 tamanho dos casulos varia de $15 \times 11$ a $18 \times 13 \mathrm{~mm}$.

0 nome da nova espécie provem da língua indígena bororo e significa "sacerdote, curandeiro"

\section{Diaguita vivianeae Righi, 1984}

Diaguita vivianeae Righi, 1984, figs. $23-30$

Material - Localidade C, 10 clitelados, 20 maduros aclitelados e 50 jovens (ZU-752A-B). Localidade D, 19 clitelados, 15 maduros aclitelados e 11 jovens ( $\mathrm{ZU}-753$ ). Localidade F, 18 clitelados, 31 maduros aclitelados e 23 jovens ( $\mathrm{ZU}-754 \mathrm{~A}-\mathrm{D}$ ) Localidade G, 1 clitelado, 20 maduros aclitelados e 92 jo vens ( $\mathrm{ZU}-755 \mathrm{~A}-\mathrm{B}$ ) Localidade $\mathrm{I}, 8$ maduros aclitelados e 17 jovens $(\mathrm{ZU}-756)$

Glossodrilus tocantinensis pola Righi, 1984

Glossodrilus tocantinensis pola Righi, 1984, figs. $19-22$.

Material - Localidade B, 18 clitelados, 9 maduros aclitela dos, 121 jovens e 6 casulos $(\mathrm{ZU}-755 \mathrm{~A}-\mathrm{B})$.

\section{REFERENCIAS}

BEDDARD, F. E., 1892 On some new species of earthworms from various parts of the world. Proc.zool.Soc.Lond., 1892:666 -706 , est. 45-46.

BEDDARD, F E., 1893. Two new genera and some new species of earthworms. Quart.J.micr.Sc. (N.S.) 34:243-278, est. 2526.

GATES, G. E., 1942. Notes on various peregrine earthworms. Buiz. Mus. Comp. Zool. Harvard, 89(3):63-144.

LUUNGSTROM, P.-0., 1972. On a new species of the ocnerodrili ne earthworm genus Eukerria from Argentina.Rev. Ecol. Biol. Sol., $g(2): 215-227$.

MICHAELSEN, W., 1891. Oligochaeten des naturhistorischen Museums in Hamburg, IV. Jahrb. Hamburg wiss.Anst., 8:299 399,1 est.

MICHAELSEN, W., 1892. Terricolen der Berliner zoologischen 
Sammlung, II. Arch. Naturg., 58(1):209-261, est. 13 .

MICHAELSEN, W., 1913. Oligochäten vom tropischen und sudlich -subtropischen Afrika, II. Zoologica, Stuttgart, 26(68): $1-63$, est. 1 .

MULLER, F, 1857 . Lumbricus corethrurus, Blirstenschwans Arch. Naturg. $23(1): 113-116$.

PANTIN, C. F A., 1964. Notes on microscopical technique for soologists. Cambridge Univ. Press, London, VIII + 76 pp.

RIGHI, G., 1968. Uber die Oligochutengattung Eukerria. Beit. neotrop. Fauna, 5(3):178-185

RIGHI, G., 1969. Sur une espèce aberrante de Glossoscoleci dae, Thamnodrilus matapi, sp. n. Pedobiologia, 9:42-45.

RIGHI, G., 1971. Sobre alguns Oligochaeta brasileiros. $\mathrm{Pa}$ péis Avulsos Zool., S. Paulo, $25(1): 1-13$.

RIGHI, G., 1972. Contribuição ao conhecimento dos Oligochaeta brasileiros. Papéis Avulsos Zool., S.Paulo, 25(18):149 -166 .

RIGHI, G., 1980. On a collection of netropical Megadrili 0li gochaeta. Stud. neotrop. Fauna (no prelo).

RIGHI, G., 1982a. Adições ao gênero Glossodrilus (Oligochaeta, Glossoscolecidae) Rev.bras.Zool., S.PauZo, 1(i): 5564 .

RIGHI, G., 1982b. Pontoscolex (Oligochaeta, Glossoscoleci dae), a new evaluation. Stud. netrop. Fauna (no prelo).

RIGHI, G., 1983. Oligochaeta Megadrili da Chapada do Guima räes, Mato Grosso. Bolm.Zool., Univ.s.Paulo (no prelo)

RIGHI, G., 1984. Oligochaeta Megadrili da região centro-oeste de Mato Grosso, Brasil. Bolm.Zool., Univ.s.Paulo (no prelo)

RIGHI, G. et all., 1976. Glossoscolecidae (Oligochaeta) do Instituto Nacional de Pesquisas da Amazónia. Acta Amazôni ca, $6(3): 335-367$.

RIGHI, G. et all., 1978. Oligochaeta (Annelida) do Instituto Nacional de Pesquisas da Amazónia. Acta Amazônica, 8 (3), Supl. $1: 1-48$.

ROSA, D., 1895. Viaggio del dottor Alfredo Borelli nella Republica Argentina e nel Paraguay - 0ligocheti terricoli Bolz. Mus. 20ol. Torino, 10(204):1-3.

ROSA, D., 1896. Terricoli netropicali. Mem.R.Accad.Sc.Torino (2) $45: 89-152,1$ est. 

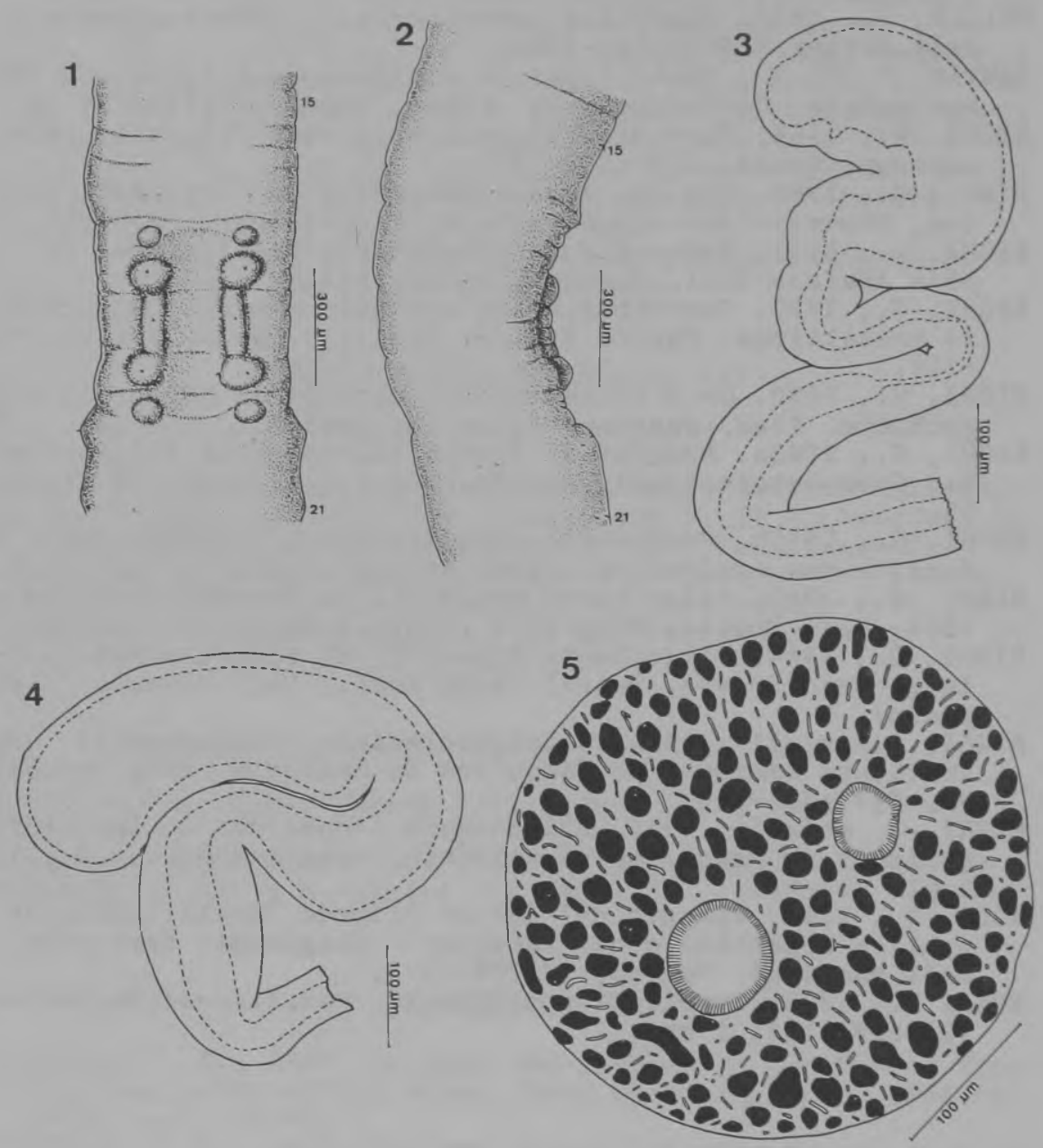

Eukerria emete: Figs. 1-2, vistas ventral e lateral dos segmentos XV-XXI; Figs. 3-4, espermatecas de $7 / 8$ (preparação gli cerínica); Fig. 5, corte transversal de uma glandula calcîfe ra. 

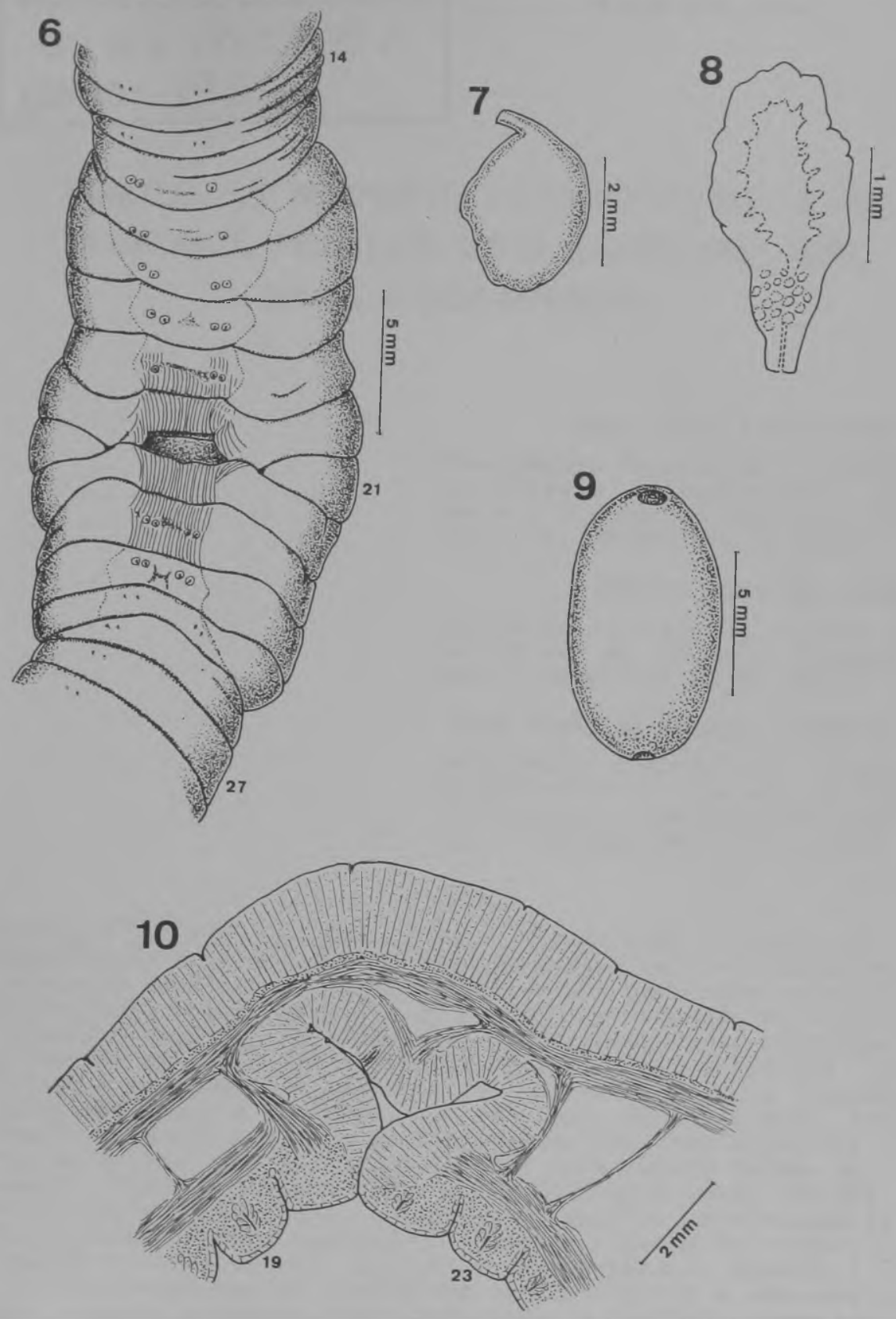

Chibui bari: Fig. 6, vista ventral dos segmentos XIV-XXVII ; Fig. 7, glândula calcífera de VIII; Fig. 8, espermateca de $7 / 8$ (preparação glicerínica); Fig. 9, casulo; Fig. 10, corte sagital de XIX-XXIII na regiấo de uma câmara copulatória. 
